\title{
O corpo moçambicano cindido: história, mito e ficção em As Duas Sombras do Rio, de João Paulo Borges Coelho
}

\author{
Carmen Lucia Tindó Secco \\ Universidade Federal do Rio de Janeiro (UFRJ)
}

\begin{abstract}
RESUMO: A FICÇÃO DE JOÃO PAULO BORGES COELHO EVIDENCIA UM CORPO MOÇAMBICANO CINDIDO ENTRE O SUL E O NORTE, ENTRE VELHAS TRADIÇÕES E NOVAS FORMAS DE ENTENDER O CONTEXTO HISTÓRICO DE MOÇAMBIQUE. PROCURA, ASSIM, ROMPER COM AS DICOTOMIAS BINÁRIAS, NEGOCIANDO IDENTIDADES EM MEIO A FRONTEIRAS TÊNUES E ESGARÇADAS. O ROMANCE AS DUAS SOMBRAS DO RIO APRESENTA ALGUMAS ALEGORIAS E METÁFORAS PARA REFLETIR ACERCA DA RELAÇÃO ESPAÇOTEMPORAL, DO IMAGINÁRIO CULTURAL E DO UNIVERSO MÍTICO-RELIGIOSO QUE PERMEIAM A SOCIEDADE MOÇAMBICANA.
\end{abstract}

ABSTRACT: THE FICTION OF JOHN PAUL BORGES COELHO SHOWS UP A MOZAMBICAN BODY SPLIT BETWEEN THE SOUTH AND THE NORTH, BETWEEN OLD TRADITIONS AND THE NEW FORMS OF UNDERSTANDING THE HISTORICAL CONTEXT OF MOZAMBIQUE. IT TRIES TO BREAK, SO, WITH THE BINARY DICHOTOMIES, NEGOTIATING IDENTITIES AMID TENUOUS AND FRAYED FRONTIERS. THE NOVEL AS DUAS SOMBRAS DO RIO PRESENTS SOME ALLEGORIES AND METAPHORS TO REFLECT ABOUT THE RELATION SPACE-STORM, OF THE CULTURAL IMAGINARY THING AND OF THE RELIGIOUSMYTHICAL UNIVERSE THAT THEY PERMEATE THE MOZAMBICAN SOCIETY.

PALAVRAS-CHAVE: MOÇAMBIQUE, FICÇÃO, MITO E HISTÓRIA. KEYWORDS: MOZAMBIQUE, FICTION, MYTH AND HISTORY. 
oão Paulo, historiador e escritor, estreou em 2003, com o romance $A s$ duas sombras do rio. Em 2004, publicou As visitas do Dr. Valdez, obra que, em 2005, recebeu o Prêmio José Craveirinha, promovido pela Associação de Escritores Moçambicanos. Além desses livros, escreveu: Índicos indícios I e II (ambos em 2005), Crónica da rua 513.2 (2006), Campo de trânsito (2007), Hynyambaan (2008). Em 2009, foi o vencedor do Prémio Leya com o romance O olho de Herzog, cuja publicação estava prevista para o primeiro semestre de 2010. É professor e pesquisador de História Contemporânea na Universidade Eduardo Mondlane, Professor Visitante do Centro de Estudos Sociais (CES), da Universidade de Coimbra. Nasceu no Porto, mas foi cedo para Moçambique, uma vez que sua mãe e avós eram da Ilha do Ibo. Cresceu e viveu até os 18 anos em cidades moçambicanas, principalmente na Beira. Moçambique é, por conseguinte, "onde se sente em casa", como declara em diversas entrevistas. Em uma dessas, por exemplo, dada ao Jornal Notícias, da Beira (Moçambique), em 15.08.2006, o próprio escritor diz:

Para mim, a identidade não é uma coisa estática, nem feita de acordo com pressupostos teóricos que, na prática, nem sempre se verificam. Penso que nós devemos viver com todos o elementos identitários que nos circundam, não apenas no nosso meio mais próximo, mas, também, num plano mais amplo. A identidade não é uma caixa fechada, nem os seus elementos são estáticos, é uma coisa dinâmica e viva.

(COELHO, JPB. Entrevista. In: site citado, 2006)

Desse modo, podemos observar que o conceito de identidade tem, para o escritor, relação com diversidade e com processo de autoconhecimento. Ao mesmo tempo que diz respeito à individualidade de cada ser, é, também, uma construção coletiva histórico-social.

O pano de fundo da ficção de João Paulo é, recorrentemente, a história de Moçambique; muitas de suas obras se passam no período pós-1975, porém, diversas vezes, o passado colonial é também reavaliado, visto que a enunciação romanesca se vale de um hibridismo temporal que superpõe tempos históricos diferentes. A narrativa do romance $A s$ duas sombras do rio acumula vários tempos: o mítico-religioso e o histórico, sendo este plural, na medida em que o narrador repensa momentos históricos do passado colonial, embo- 
ra o cenário central seja a região do Zumbo, focalizada, principalmente, num tempo histórico pós-independência, marcado não só por dolorosa guerra civil, mas também por euforias e decepções com a FRELIMO, descontentamentos com uma majoritária administração das elites urbanas do sul do país, em detrimento das populações rurais do norte.

A escrita romanesca de João Paulo Borges Coelho evidencia um corpo moçambicano cindido entre velhas tradições e as novas racionalidades, entre o sul e o norte. Procura, assim, romper com as dicotomias binárias, negociando identidades em meio a fronteiras tênues e esgarçadas. Sua ficção se utiliza de algumas alegorias e metáforas para refletir acerca da relação espaçotemporal, do imaginário cultural e do universo mítico-religioso que permeiam a sociedade moçambicana, a saber: a água (rio e chuva); a casa (terra e nação); o fogo (sexualidade e guerra); a sombra (o inconsciente e o espírito).

Em As duas sombras do rio, a água, significando o rio Zambeze, é a linha que demarca os territórios do norte e do sul de Moçambique, o passado e o presente, as tradições e a modernidade. Leónidas Ntsato, personagem principal da estória, sintomaticamente, é quem fica entre o rio Zambeze e a tríade Zâmbia, Zimbabwe e Moçambique, espaços onde terra e água são representadas pela barragem de Cahora Bassa.

Leónidas vivia cruzando o rio, em sua almadia, a pescar. O romance começa, justamente, quando ele é encontrado, desacordado, de face na areia, na ilha de Cacessemo, no meio do Zambeze. Nesse o espaço intermediário, de olhos postos na terra, mergulha em perturbações, estranhezas, perplexidades, que alegorizam as tensões provocadas pela carência ao redor. Pescadores sem peixes, águas represadas, populações com fome, a miséria causada pela guerra. Histórias de divisões entre a memória e o presente, entre deuses e homens, entre os próprios homens.

O majestoso Zambeze, suas águas cavaram um fosso, separando o mundo da cobra, feminino, milenar, cheio de sabedorias e matrizes primordiais, e o mundo do leão, do fogo, do poder, da modernidade do sul. Esses dois mundos, frente às contradições e guerras, no presente, não se encontram, nem se complementam; ao contrário, se opõem, evidenciando fraturas profundas no corpo social moçambicano: "O rio é a fronteira entre os dois poderes que lutam dentro dele, do personagem principal. É ali que começa um e acaba o outro, ali acaba o norte e começa o sul". (COELHO, JPB, 2003, p. 38) 
A construção da represa de Cahora Bassa e o cotidiano da guerra colocam as personagens - e não só Leónidas Ntsato - em uma situação de conflito, tensão e deslocamento. As metáforas da água e do fogo passam, então, a denotar desequilíbrio e instauram uma desarmonia na região, dividindo "as duas sombras do rio". Sombras que se tornam uma polissêmica metáfora, simbolizando não só as margens do rio, mas o inconsciente histórico e mítico, remetendo, também, ao mundo dos espíritos que fazem parte das crenças locais, baseadas nos cultos aos antepassados e aos ancestrais.

Além das metáforas da água, do fogo e das sombras, a da casa, tendo o significado de nação, com suas tradições e racionalidades, está, também, presente neste romance. Em muitas de suas partes, o choque ideológico e religioso entre tradicionalistas e materialistas é evidente. A enunciação romanesca vai apontando, de modo crítico, para essas questões como, por exemplo, quando a personagem Sigaúke, o administrador, se encontra dividido entre mitos e religiosidades das tradições moçambicanas originárias e o materialismo imposto pelo governo da primeira fase da Independência: " $\mathrm{Na}$ escola de administradores me ensinaram que era preciso acabar com os obscurantistas, fazendo valer o materialismo e a lei"'(COELHO, JPB, 2003, p. 47). No entanto, são as duas personagens que lidam com espíritos que se conjugam para ajudar a "aparente loucura" do pescador Leónidas: Harkiriwa, uma refugiada rural, ligada à terra, que vem do Norte, e Gomanhundo, o curandeiro da cidade, cujo espírito é o de um frade dominicano português do início do século XIX. Essa fusão de um curandeiro africano incorporando o espírito de um frade europeu é bem sintomática do hibridismo religioso ali existente, decorrente da mesclagem das religiões africanas ancestrais com as crenças impostas pelos colonizadores.

A cisão constatada não foi apenas causada pelas guerras, pois, desde o colonialismo, o norte e o sul de Moçambique já se encontravam cindidos. A guerra civil apenas aumentou essa fissura. A unidade interna, durante a luta anticolonial, já se revelava fraturada, dividida entre as ações da FRELIMO e da RENAMO, o que, internamente, também refletia as dicotomias externas do contexto mundial da Guerra Fria, incentivada por polarizações extremadas entre capitalismo e socialismo. Criticamente, a enunciação romanesca vai problematizando e desfazendo tais binarismos redutores. 
A metáfora da "casa-país", do mesmo modo que a almadia do pescador Leónidas, está à deriva, à procura da própria identidade. Natureza e cultura também se degladiam: "Carneiros hidráulicos inauditos, que iam contra a natureza, trazendo a água para cima quando é certo que a natureza só a faz descer..." (COELHO, JPB, 2003, p. 88). Uma rede de micro-histórias e personagens procura preservar memórias e religiosidades, buscando conservar a multifacetada identidade, em meio a esfacelamentos políticos, culturais, sociais.

Contracenam no espaço romanesco, além do protagonista - o pescador Leónidas Ntsato -, personagens típicas, como: o administrador Singaúke; a enfermeira Inês; a refugiada rural Harkiriwa; o curandeiro da cidade Gomanhundo; o superintendente Million, responsável pelo Parque Nacional do Baixo Zambeze; a congolesa Mama Mère, a maior comerciante de Feira, também metida com contrabandos de marfim e diamantes; o caçador Zé Mantia; MeiaChuva, o combatente padrão; os padres, fortes como touros, que se acoitavam com jovens mulheres e, com seus cânticos, maravilhavam os filhos da terra:

Nas suas batinas castanhas, eram os padres fortes como touros. Findo o período de reflexão, atiravam-se então às jovens mulheres das redondezas com uma voracidade redobrada pela contenção que, quando às claras, a si próprios impunham, na maior parte do tempo. E essas raparigas cedidas pelas aldeias, que já não pertenciam ao seu mundo velho e ainda procuravam achar um lugar certo no mundo novo, submetiam-se na crença de que eram estes jogos parte do ritual que ainda estavam a aprender.

(COELHO, JPB, 2003, p. 88)

O narrador, em terceira pessoa, vai narrando histórias, mitos, comentando os fatos históricos, com uma focalização interventiva que se manifesta não só por reflexões e explicações, mas por descrições belíssimas e detalhadas, assim como por esclarecimentos e comentários irônicos, que se apresentam entre parênteses, conforme aparece no exemplo a seguir:

Mas hoje é um dia especial. Leónidas Ntsato decidiu-se a mudar a situação. Resolutamente, atravessou a praça em direcção ao edifício (só os desvairados podem avançar assim, como se tivessem um objectivo amadurecido, embora o 
escolham de entre outros objectivos de forma aparentemente arbitrária). Hesitou ainda no primeiro degrau, mas foi pouca coisa.

(COELHO, JPB, 2003, p.45)

A narração se tece por meio de um ponto de vista onisciente que, em algumas ocasiões, por intermédio do discurso indireto livre, perde, em parte, a distância característica do narrar heterodiegético, se acumpliciando aos dramas das personagens que encenam os horrores vivenciados pela gente daquela província moçambicana, durante a guerra civil. Esse narrador entremeia a seu discurso micro-histórias, nas quais estão presentes diálogos de personagens que denunciam situações de violência e os estragos provocados como, por exemplo, a descaracterização de mitos tradicionais, entre outros:

Passada aquela pantanosa barreira que garante a completa solidão (quem ousaria segui-lo através daquela visão do inferno, através daquele cemitério de gente antiga disfarçado de canavial?) Ntsato entra agora numa pequena ilha de rasteiros capins verdes que o sol formou, porque a inexistência de arvoredo permitiu que ele até ali baixasse os seus raios e secasse as abundantes lamas (o lugar onde estariam as canas dos que partiram e ali se tivessem finado como os outros).

(COELHO, JPB, 2003, p.42)

- E que vejo eu na minha terra? - prossegue o Kanyemba pela boca de Joaquina. - Vejo machambas de onde mal sai comida, vejo elefantes que mal procriam (nunca se viu tão poucos elefantes nesta terra como agora), mulheres com os seios secos e mirrados de onde não pinga mais o leite, almadias furadas junto à margem do rio, celeiros vazios (...)

(COELHO, JPB, 2003, p. 149)

Em trechos como esses citados, paisagens devastadas são descritas e denunciadas; alguns mitos, como o do espírito do grande leão Kanyemba, são revisitados. As descrições entremeiam o narrar e são muito expressivas. João 
Paulo Borges Coelho é exímio não só na arte de narrar, mas também na de descrever.

A narrativa de As duas sombras do rio cumpre um papel de resistência à perda das tradições moçambicanas, provocada pelos conflitos bélicos e pela construção da represa de Cahora Bassa que trouxe componentes de modernidade ao Zambeze. Em diversas passagens, o narrador assume uma linguagem metafórica, questionando, por exemplo, a ação da Igreja Católica no processo de colonização, demonstrando, ironicamente, como esta se tornou a Casa de um único Deus e de uma só religião - a dos invasores -, tendo abafado muitos cultos e religiosidades dos povos de Moçambique:

Cânticos doces, complexos que baixavam suavemente para logo subirem agudos como aquela água que desafiava a natureza. Belas como os cânticos eram as casas, sobretudo a Casa, imponente na sua altura, a gruta perfeita onde os cânticos ganham a dimensão mágica das conversas com Deus. A Casa que revelava um cuidado extremo e uma imaginação desvairada no seu detalhe, onde os diabos esculpidos eram cobras e leões, apesar de tudo, já bichos daquela terra.

(COELHO, JPB, 2003, p. 89)

Outra metáfora, a da carne, entendida como sexualidade pervertida e reprimida, encontra-se presente nos muitos corpos sem autonomia, sem liberdade que povoam a narrativa. São corpos mutilados e silenciados, tiranicamente subjugados e torturados. Suas vidas foram destruídas; suas possibilidades de sonho, interrompidas, tanto por invasores externos, como por hordas internas que, masoquistamenete, se compraziam com a violência, exercendo um erotismo macabro. Sobreviver: eis a questão, em meio aos medos e crueldades decorrentes de uma guerra fratricida que gerou inúmeras perplexidades.

Buscando alternativas para vencer o desencanto provocado por tais contextos de brutalidade, o narrador afirma: "não há um só destino, há sempre um destino atrás do outro, todos os dias, sucedendo-se ou correndo como água do rio, e a sucessão de todos os destinos principais e paralelos é a história.” (COELHO, JPB, 2003, p. 100). Essa definição de história o narrador, ao longo do romance, vai desconstruindo, na medida em que vai sempre contrapondo diferentes versões históricas, o que leva a múltiplos pontos de vista e 
à certeza de que os destinos se cruzam, transversalmente, se interpenetrando, em descontinuidades e rupturas.

O enfoque histórico que se depreende no romance $A s$ duas sombras do rio se aproxima do olhar da Nova História, uma vez que opera com mitos, subjetividades, memórias e relatos esgarçados, revisitações do passado a partir de silêncios, lacunas e fragmentos que resistiram aos séculos e permaneceram condensados em bolsões do imaginário histórico-cultural. Muitas dessas sobrevivências se encontram em configurações míticas que atravessaram tempos e aldeias, inspirando profecias. Um exemplo presente no romance em questão é o antigo mito do grande leão, cujo espírito se incorpora em algumas personagens, alertando para sérios problemas existentes no Moçambique pós-independência:

Kanyemba, o grande leão, tinha algumas coisas a dizer através da sacerdotisa Joaquina M'boa - mataram a terra e todas as coisas. Matam-se agora uns aos outros. E quando há este ódio entre vizinhos, quando as aldeias se inimizam desta maneira, quando a família se acaba, é porque se aproxima o vazio e o fim.

(COELHO, JPB, 2003, p. 151)

Encontram-se ameaçados tanto o fogo sagrado - que configura o universo ígneo do mítico leão -, como a água primordial da memória - que constitui o mundo feminino da cobra ancestral -, metaforizada pelo rio que corta o país, percorrendo-o, dividindo-o, mas também o unindo e o ligando. Avaliando os percalços e entraves do presente, continua o narrador:

O mal era dos tempos e da dificuldade em tomar uma direção. Antigamente, as coisas eram certas e claras, estava tudo arrumado nos seus lugares. Sabíamos de onde vínhamos e isso ajudava-nos a ir percebendo para onde íamos. Os passos eram certos, embora só aos deuses coubesse adivinhar quando vinha a chuva.

(COELHO, JPB, 2003, p. 223)

Depreende-se, por conseguinte, que uma história de Moçambique pós-independente se encontra, pulsante, em meio à guera civil, nas margens e som- 
bras do rio Zambeze que corre para o mar. Uma história que acumula vários tempos, indo das atrocidades do contexto das lutas entre a FRELIMO e a RENAMO, após a independência, às da época da escravidão e do tráfico negreiro:

O Zambeze é uma larga e majestosa fita de prata que separa a terra do céu. Uma grande cobra que vem de Angola e corre para o mar. Da boca dessa cobra gerações e gerações de antepassados se despediram desta vida e penetraram nas brumas do além amarrados uns aos outros...

(COELHO, JPB, 2003, p. 258)

Vieram homens brancos do outro lado do mar, contra o fluxo descendente e avassalador, e treparam por ali acima a enviar a carga humana para a foz e dali para este outro lado do mar...

(COELHO, JPB, 2003, p. 259)

As duas sombras do rio, distantes uma da outra - projeto impossível de reunião até a organização da paz, em outubro de 1992, com o fim da guerra civil, mas que, entretanto, continuam, ainda hoje, em pleno século XXI, afastadas, alegorizando novas perplexidades e necessidades de muitas negociações para que o complexo processo de reconstrução identitária de Moçambique possa fluir, em toda sua diversidade.

O discurso do narrador de $A s$ duas sombras do rio apresenta, por vezes, uma dicção interventiva, que vai comentando a história ficcionalizada, fazendo a mediação entre os acontecimentos político-sociais e a representação literária dos mesmos. Mas, no desfecho do romance, abandona inteiramente as interferências, optando por manter abertos os vãos e desvãos de interpretar o que a memória traz do passado e o que a história deixa para ser invenção...

É afinal tão simples a história deste rio. Tão simples e, todavia, levou séculos a desenrolar-se, pois os deuses gostam de contá-la devagar. Devagar, também, Leónidas Ntsato mergulhou nele, nessa noite, ficando nós sem saber se procurava chegar à Cacessemo para alongar a sua perplexidade nessa fronteira, se 
lhe bastava perder-se nas águas para ganhar a tranquilidade e a indiferença dos afogados.

(COELHO, JPB, 2003, p. 260)

O surpreendente final romanesco alonga a perplexidade do narrador, estendendo-a ao leitor: Leónidas se atirara ao Zambeze e morrera afogado?! Ou mergulhara para buscar uma "terceira margem" na Ilha de Cacessemo?! "Enlouquecera" ou fora possuído pelos espíritos do leão e da jiboia, mitos moçambicanos ancestrais, opostos e inconciliáveis ?!

As dimensões histórica, literária e mítica se entrelaçam no espaço ficcional de As duas sombras do rio. A focalização romanesca deixa de ser intenvertiva; não conseguindo o narrador explicar mais - como, por vezes, fazia -, racionalmente, o acontecido. A dimensão animista invade a ficção e esta se vale do mítico para alegorizar, criticamente, a história.

Segundo crenças antigas do imaginário mítico de determinadas etnias moçambicanas, aqueles que "morrem mal" se tornam espíritos vingativos que voltam para ajustar contas. Há animais míticos, como o grande leão, o mambo mphondolo, que pode encarnar em um vivente, expressando, por meio da possessão deste, seu descontentamento com desequilíbrios sociais, culturais, climáticos ocorridos em aldeias e espaços da região. "Os indivíduos possuídos começam, de súbito, a sentir sintomas estranhos, dizendo coisas que ninguém entende, acabando por se lançar em direção ao local onde viveu o dono do espírito". (OLIVEIRA. Cf. site citado em nossas Referências Bibliográficas). No caso de Leónidas Ntsato, há um conflito, pois ele, ao mesmo tempo, incorpora o espírito do leão e o da cobra. Como Leónidas (leão), ele, alegoricamente, expressa o estranhamento e a perplexidade diante de tantas mortes e atrocidades. Como Ntsato (a jiboia mítica), se insurge contra os "carneiros hidráulicos" que verticalizaram o curso das águas, criando a represa de Cahora Bassa. Talvez seu mergulho tenha sido uma forma metafórica de evidenciar a necessidade de Moçambique recuperar o equilíbrio cósmico, representado por ntsato, a jiboia ancestral, protetora das regiões atravessadas pelo rio Zambeze.

Concluindo, podemos interpretar a "loucura" de Leónidas como uma grande recusa alegórica, como uma manifestação "a contrapelo” da história oficial 
que, desde o passado colonial até a sangrenta guerra civil, afogara mitos e episódios históricos do território do Zumbo e das margens do Zambeze. Elegendo a "terceira margem do rio", a personagem dá primazia aos sentidos poéticos da existência, em categórico repúdio à violência e à opressão vivenciadas por aquela região moçambicana, metonímia de todo o país.

\section{Referência Bibliográfica}

ABDALA JR., Benjamin. Literatura, história e política. SP: Ed. Ática, 1989. . Fronteiras múltiplas, identidades plurais. SP: Ed. SENAC, 2002.

APPIAH, Kwame Anthony. Na casa de meu pai. A África na filosofia da cultura. Rio de Janeiro: Contraponto, 1997.

BENJAMIN, Walter. Magia e técnica, arte e politica. Trad. Sergio Paulo Rouanet. São Paulo: Brasiliense, 1984.

BURKE, Peter (1977). "As fronteiras instáveis entre história e ficção". In: Aguiar, Flávio et alii (Org.). Gêneros de fronteira: cruzamento entre o histórico e o literário. São Paulo: Xamã, 1997.

CHAVES, Rita. A formação do romance angolano: entre intenções e gestos. São Paulo: Departamento de Letras Clássicas e Vernáculas da USP, 1999.

COELHO, João Paulo. As duas sombras do rio. Lisboa: Caminho, 2003. Entrevista no blog Macua, 2006. http://www.macua.

blogs.com/...todos/.../joao_paulo_borges_coelho_entrevista.doc Acesso: $16 / 12 / 2009$.

"E depois de Caliban? A história e os caminhos da literatura no Moçambique contemporâneo". In: GALVES, Charlotte et alii. ÁfricaBrasil: caminhos da língua portuguesa. Campinas: UNICAMP, 2009. pp. 57-68.

- Entrevista ao escritor moçambicano João Paulo Borges Coelho, pu-

blicada na Revista Metamorfoses 10. Rio:Cátedra Jorge de Sena para Estudos Literários Luso-Afro-Brasileiros; Lisboa: Editora Caminho,novembro/ 2009. ISSN: 0875-019X; ISBN 972-21 1565-0. pp.167-178.

GALVES, Charlotte et alii. África-Brasil: caminhos da lingua portuguesa. Campinas: UNICAMP, 2009

MACÊDO, Tania e MAQUEA, Vera. Literaturas de lingua portuguesa - Marcos e Marcas - Moçambique. São Paulo: Arte \& Ciência, 2007.

MENDONÇA, Fátima. Literatura moçambicana: a história e as escritas. Maputo:

Universidade Eduardo Mondlane, 1988. 
LE GOFF. História e memória. Tradução de Bernardo Leitão et alii Campinas: UNICAMP, 1990.

NOA, Francisco. Império, mito e miopia: Moçambique como invenção literária. Lisboa: Caminho, 2002.

NOVAES, Adauto (org.). Tempo e história. São Paulo: Companhia das Letras, 1992.

OLIVEIRA, Carlos Ramos. In: http://www.macua.org/livros/tuara1.html AcesSo:20/10/2009.

PADILHA, Laura. Novos pactos, outras fições: ensaios sobre literaturas afro-luso-brasileiras. Porto Alegre: EDIPUCRS, 2002.

REVISTA VIA ATLÂNTICA. Publicação da Pós-Graduação em Estudos Comparados de Literaturas de Língua Portuguesa da Faculdade de Filosofia, Ciências e Letras da USP. São Paulo: Departamento. n.3 (1999) e n. 5 (2002). ISSN: 1516-5159.

RIBEIRO, Margarida Calafate e MENESES, Paula. Moçambique: das palavras escritas. Porto: Afrontamento, 2008.

SANTOS, Boaventura de Sousa. Pela mão de Alice. 2.ed.SP: Cortez, 1991. SECCO, Carmen Lucia Tindó. A magia das letras africanas. 2. ed. Rio: Quartet, 2008. ZAHAR, Renate. Colonialismo e alienação. Lisboa: Ulmeiro, 1976. 